obtained on reduction of hepatoflavin at $p \mathrm{H} 7 \cdot 3$ is given.

Another striking coincidence is represented by the fact that the normal potential of the lactate-pyruvateenzyme system ${ }^{6}$ is almost identical with the normal potential of the flavins at the same $p H\left(E_{0}^{\prime}\right.$ being respectively $-200 \mathrm{mv}$, and $-219 \mathrm{mv}$. (hepatoflavin) at $p H$ 7). The relation between the flavin potential and the equilibrium conditions in enzyme-substrate systems is under investigation.

Courtauld Institute of Biochemistry, Kurt G. Stern.

Middlesex Hospital Medical School, London, W.1.

Dec. 4.

1. K. Stern, NATURE, 182, 784, Nov. 18, 1933.

K. G. Stern and G. D. Greville, Naturwiss., 21, 720 ; 1933.

R. Bierich, A. Lang and A. Rosenbohm, ibid., 21, 496 ; 1933. R. Chambers, L. V. Beck and D. E. Green, J. Exp. Biol., 10, 142 ; 1933.

' R. K. Cannan, B. Cohen and W. M. Clark, Suppl. 55, Publ. Health Rep. Washington; 1926.

R. Wurmser and N. Mayer-Reich, J. Chim. Phys., 30, 249; 1933 J. P. Baumberger, J. J. Jürgensen and K. Bardwell, J. Gen. Physiol. 16,$961 ; 1933$. I. Banga, K. Laki and A. Szent-Györgyi, Z. physiol. Chem., 217,43 ; 1933

\section{A Camera Method for Charting Quadrats}

THe botanical analysis of pastures by means of quadrats should combine both speed and accuracy. Up to the present, the rapid methods have been somewhat subjective, and in many cases the results obtained cannot be compared closely owing to variation in the personal factor. The more intensive objective analyses, on the other hand, have sacrificed speed to greater accuracy. The following method of quadrat charting has accordingly been devised in order to secure both speed and accuracy, and is of special value in the charting of open tufted swards such as those commonly found in South Africa.

The apparatus consists of a wooden square metre quadrat to which is screwed a tressel with an extra leg at each end to secure rigidity. The precise form of this tressel is unimportant; that it should be rigid is all-important. The tressel supports a camera directly over and focused towards the centre of the quadrat. The image of the quadrat is thrown not on to the usual frosted focusing glass, but on to a sheet of plain glass upon which is secured a sheet of transparent (or oiled) squared paper. The image of the vegetation within the quadrat can then be traced by pencil with ease and accuracy upon the paper.

In using the apparatus, it is desirable to have two workers, one tracing the outline of the plants (basal cover or otherwise), the other moving the foliage of the grass, etc., to render the outlines clear to the tracer, and, if necessary, identifying the species. For ease in working, the light-hood screening the image should fit closely to the top of the camera, and be provided with eye-pieces and an arm-hole at the side. Both vertical and lateral adjustments of the camera are provided for on the frame, but once the correct position is obtained no further adustments are necessary.

The method has several advantages :

(1) The apparatus is readily constructed from simple material. Any half-plate camera can be employed, provided it has a suitable wide-angle short focus lens (approximately 5-4).

(2) The apparatus is collapsible and can be fastened into a small bundle for moving long distances ; for short distances, the whole apparatus when set up can be moved with ease.

(3) Once adjusted, no further adjustments are necessary.

(4) Photographs of the charted vegetation may be obtained if necessary by merely substituting the dark slide for the glass plate.

(5) It is both rapid and accurate in use. A tufted sward, composed of a number of different species, can be charted and identified in ten to fifteen minutes.

\section{J. W. Rowland.}

J. M. HECTOR.

Department of Agricultural Botany,

The University,

Pretoria.

Dec. 20.

\section{Diethyl Peroxide as a Pro-Knock}

In spite of the considerable literature, there seems to be no special reference ${ }^{1}$ to the properties of diethyl peroxide as a pro-knock. In view of its possible importance in some theories of hydrocarbon combustion, it was of interest to investigate its behaviour in the engine. Diethyl peroxide is a violent proknock, slightly more potent than amyl nitrite at the same concentration. Its knocking action is inhibited by lead ethyl.

Ethyl hydrogen peroxide is likewise definitely a pro-knock. In spite of the ease of thermal decomposition, 30 per cent of hydrogen peroxide was found to have definite, but very slight, pro-knock tendency.

Apart from the possible theoretical significance of these facts, which is being discussed elsewhere, it seems desirable to record the pronounced knocking behaviour of this class of compounds.

A. Egerton.

Dept. of Thermodynamics,

A. R. UBBELOHDE.

Clarendon Laboratory, Oxford.

Jan. 24.

${ }^{1}$ Cf. possibly Withrow and Rassweiler, J. Ind. Eng. Chem., December, 1933.

\section{Three Discharges of Ball Lightning}

AT 4.15 p.m. on January 11, the phenomenon of ball lightning occurred at the house of Mr. Joseph M. Wreath, Ballymoney, Co. Antrim.

A first ball exploded against the corner of a metalbound tea chest just inside the wide open door of a coach-house in a walled-in yard attached to the dwelling-house. A second exploded a minute or two later against a ladder leaning against the same coachhouse. A third entered a ground floor room of the dwelling-house, having come down the chimney against the up draught due to a fire burning at the time. It exploded in the fireplace.

The balls outside were seen by Mr. Wreath and a friend, who describe them as orange-red and as being of about the size and having the velocity of a cricket ball. That indoors was seen by two ladies.

A wireless aerial is attached to the chimney stack by which the third ball entered the dwelling-house.

Thirlmore, Marshall Holmes.

Innisfayle Road, Belfast. Jan. 20. 